\title{
In vitro evaluation of anti-inflammatory and anti- diabetic effects of Euphorbia tithymaloides ethanol extract
}

\author{
Theresia Galuh Wandita ${ }^{1}$, Najuma Joshi ${ }^{1}$, Joseph dela Cruz $^{2}$, Seong Gu Hwang ${ }^{1 *}$
}

1. Laboratory of Applied

Biochemistry, Department of Animal Life and

Environmental Science, Hankyong National University, South Korea, 327 Jungang-ro, Anseong-si, Gyeonggi-do, 456-749, South Korea

2. Department of Basic Veterinary Sciences, College of Veterinary Medicine, University of the Philippines Los Banos, Philippines

Submitted: 11-11-2017

Revised: 25-12-2017

Accepted: 06-01-2018

*Corresponding author Seong Gu Hwang

Email:

sghwang@hknu.ac.kr

\begin{abstract}
Euphorbia tithymaloides L., a native plant of tropical and subtropical areas in Asian countries which has been known as traditional medicine with a wide range of healing effects, such as anti-hemorrhagic, anti-diabetic, anti-bacterial, anti-inflammatory, and anti-tumor activity. The present study was orchestrated to evaluate the potential anti-inflammatory and anti-diabetic effects of Euphorbia tithymaloides ethanol extract (ETE). The antiinflammatory and anti-diabetic activities were studied through the treatment of RAW 264.7 murine macrophages cells and 3T3L1 adipocytes with various concentrations of ETE $(50,100,200$, and $400 \mu \mathrm{g} / \mathrm{mL}$ ). The results showed that ETE below $400 \mu \mathrm{g} / \mathrm{mL}$ has no negative effect on RAW 264.7 cell proliferation. ETE decreased nitric oxide production in macrophages RAW 264.7 cell line and reduced the protein expression of cyclooxygenase 2, interlukin-6, inducible nitric oxide synthase, tumor necrosis factor- $a$ and nuclear factor-kB in a dose-dependent manner. In 3T3-L1 preadipocytes, the increase of ETE concentration did not affect cell viability, but significantly enhanced adipogenesis through increase in differentiation and the expression of peroxisome proliferator-activated receptor gamma, CEBPa, glucose transporter type 4 and insulin receptor substrate 1 . ETE also stimulated 2-NBDG uptake through activation of the insulin signaling pathway through insulin-sensitizing PPARy agonists in a dose-dependent manner. In conclusion, our findings that ETE has immunomodulatory activity and anti-diabetic effects, which can be used for treating inflammation and type II diabetes.
\end{abstract}

Keywords: Anti-diabetic, Euphorbia tithymaloides, Glucose uptake, Immunomodulation, Nitric oxide

\section{INTRODUCTION}

Medicinal plants have been used since ancient times. Owing to the side effects of some modern medicines, The World Health Organization Expert Committee has recommended the use of traditional medicinal plants for the treatment of some diseases. Ethno-botanical knowledge suggests that approximately about 800 plants have immunomodulatory and anti-diabetic potential (Singh, 2011). Medicinal plants may provide a good alternative for treating diabetes mellitus and inflammation, and counter the high cost, side effects, and poor availability of the currently available drugs in developing countries such as the Philippines.
Inflammation is the most common type of response employed by the body as a defense mechanism against harmful stimuli originating from the surrounding environment. The inflammatory response is characterized by the coordinated activation of various signaling pathways that regulate the expression of both pro- and anti-inflammatory mediators in resident tissue cells and leukocytes recruited from the blood. Nuclear factor kappa B (NF$\mathrm{kB}$ ) plays an important role in the activation of genes involved in the immune responses. This transcription factor increases many cytokines gene expression, such as interleukin (IL-1 $\beta$, IL2 , IL-6, IL-8, and IL-12), cyclooxygenase (COX)-2, and tumor necrosis factor (TNF) $-\alpha$. 
They possess NF-kB binding sites and have been shown to be transcriptionally regulated by NF-kB. Moreover, NF-kB transcriptionally regulates the gene for inducible nitric oxide synthase (iNOS) (Ghosh et al., 2014).

Diabetes mellitus (type II diabetes) is caused by defective insulin production or insulin resistance. The prevalence of diabetes has increased at an alarming rate in Asian countries including the Philippines. In 2016, the death of, 33.2 million people in the Philippines was attributable to diabetes. Adipogenesis is regulated by a complex gene expression such as peroxisome proliferator-activated receptor gamma and CCAAT/enhancer binding protein $(\mathrm{CEBP} \alpha)$. It is considered as a nuclear receptor in adipocytes (Winrow et al., 1996; Rosen et al., 2000; Vergara et al., 2015). Adipocytes are turning up as a potential medicine for treating diabetes mellitus (Hassan et al., 2007). The mechanism involves insulin-triggered relocalization of a glucose transporter (GLUT4), which is highly expressed, and insulin-stimulated glucose uptake in adipocytes by the rapid translocation of GLUT4 from intracellular stores to the plasma membrane (Choi et al., 2009; Manaharan et al., 2013).

Euphorbia tithymaloides belongs to the family Euphorbiaceae. It is a perennial succulent spurge that has been used to treat inflammation and cancer in Asian countries, especially the Philippines. The root of this plant has been shown to be effective against intestinal worms and to reduce inflammation when ingested (Jain and Srivastava, 2005; Heinrich et al., 1992; Adzu et al., 2008). The extracts of the leaves have been used to treat conditions such as asthma, laryngitis,and persistent coughing. In an earlier study, various bio-active compounds were found in this plant such as octacosanol, betasitosterol, cycloartenone, and oxime. One of these, octacosanol, significantly decreased the pro-inflammatory cytokines genes expression in in-vitro and in-vivo studies (Oliveira et al., 2012; Castaldo and Capasso, 2002; Njamen et al., 2003). Galactose-specific lectin, also contained in this plant might be useful for the treatment of diabetes mellitus as mentioned by Joseph and Priya (2011). Furthermore, there have been no reports on the anti-inflammatory and antidiabetic activities of this plant in macrophages and 3T3-L1 cell. Thus, our present study aimed to evaluate the potential effects of $E$. tithymaloides ethanol extract as an immunomodulatory and anti-diabetic herbal medicine.

\section{MATERIALS AND METHODS Reagents}

RAW 264.7 macrophages cell line and 3T3-L1 mouse preadipocyte cells were obtained from ATCC (Manassas, VA, USA). Dulbecco's modified Eagle's medium (DMEM), bovine calf serum (BCS), phosphate buffer saline (PBS), fetal bovine serum (FBS), and 2-(N-(7nitrobenz-2-oxa-1, 3-diazol-4-yl) amino)-2deoxyglucose (2-NBDG) were purchased from GIBCO/Invitrogen (Carlsbad, CA, USA). Lipopolysaccharide (LPS), bovine serum albumin (BSA), isobutyl-3-methyl-xanthine (IBMX), insulin (INS), and dexamethasone (DEX), were acquired from Sigma-Aldrich (St. Louis, MO, USA). Primers used in these experiments were purchased from Macrogen (South Korea). The antibodies used in these experiments were obtained from Cell Signaling Technology (Danver, Massachusetts, USA).

\section{Plant material}

The dried whole plant of E. tithymaloides was powdered and successively extracted in $80 \%$ of ethanol for 24h. The ethanol extract of this plant (ETE) was filtered, and evaporated under vacuum. The freeze-dried sample was powdered and stored at $-80^{\circ} \mathrm{C}$ until use. Hereafter, the extract was mixed with the medium.

\section{Cell culture and cell viability assay}

RAW 264.7 macrophages cell line and 3T3-L1 preadipocytes cells were grown in DMEM with 10\% FBS and DMEM with 10\% BCS, respectively. To activate macrophages, $10 \mu \mathrm{L} / \mathrm{mL}$ of lipopolysaccharide was added to the culture medium. To induce the differentiation of 3T3-L1, the cells were cultured with fresh induction of $1 \mu \mathrm{M}$ dexamethasone, $0.5 \mathrm{mM}$ isobutyl-3-methylxanthine, and $10 \mu \mathrm{L} / \mathrm{mL}$ insulin.

Cell viability was determined by using cell counting kit (CCK)-8 assay (Dojindo Laboratories, Japan). The cells, RAW 264.7 macrophages cells $\left(1 \times 10^{5}\right.$ cell/well $)$ and 3T3-L1 preadipocytes cells $\left(1 \times 10^{4}\right.$ cell/well $)$ were 
seeded and treated with various concentrations

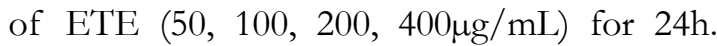
CCK solution $(1 \mu \mathrm{g} / \mathrm{mL})$ was then added to each well. The absorbance was quantified at $450 \mathrm{~nm}$ by using an ELISA microplate reader. Six replicates were performed for each assay.

\section{Anti-inflammatory activity}

Anti-inflammatory activity was determined from the nitrite oxide production and the expression of pro-inflammatory cytokines. Nitric oxide production was determined as the nitrite concentration in culture medium by using a colorimetric assay. The cells were seeded in a 96-well plate and treated with different concentration of ETE. Negative control (NC) and positive control (PC) were designed to identify the effect of ETE in RAW 264.7 macrophages cells. Lipopolysaccharides were used as positive control which helps to activate the cells. After $1 \mathrm{~h}$ incubation, the cells were stimulated with $1 \mu \mathrm{g} / \mathrm{mL}$ LPS for $24 \mathrm{~h}$. The supernatant was mixed with Griess reagent, and the absorbance at $540 \mathrm{~nm}$ was measured by using an ELISA microplate reader (Tecan Infinite F50). The concentration of $\mathrm{NO}$ was calculated by reference to a linear standard curve generated from serial dilutions of sodium nitrite in working medium.

The protein and genes expression of pro-inflammatory cytokines (iNOS, COX2, IL$6, N F-k B$ and $T N F \alpha$ ) in the macrophages cell line RAW 264.7 were measured by using reverse-transcription polymerase chain reaction (R'T-PCR) and western blotting, respectively.

\section{Anti-diabetic activity}

Anti-diabetic activity was determined by a glucose uptake assay, Oil -Red -O staining, triglyceride assay, and by analyzing adipogenic markers expression. To determine the glucose uptake in 3T3-L1 preadipocytes, a modified method by Manaharan et al. (2013) was used in the present study. 3T3-L1 cells were incubated with different concentration of ETE (50, 100, 200 , and $400 \mu \mathrm{g} / \mathrm{ml}$ ) and $10 \mu \mathrm{L} / \mathrm{mL}$ insulin for $24 \mathrm{~h}$ at $37^{\circ} \mathrm{C}$ in $5 \% \mathrm{CO}_{2}$ atmosphere. Thereafter, after the addition of $250 \mu \mathrm{mol} / \mathrm{L} 2-\mathrm{NBDG}(\mathrm{N}$ (7-Nitrobemz-2-oxa-1,3-diazol-4-yl)Amino)-2deoxyglucose), the cells were incubated for a further $30 \mathrm{~min}$. To remove the excess fluorescent material in the wells, the cells were washed twice with PBS after incubation. The fluorescence retained in the cell monolayers at $540 \mathrm{~nm}$ using an ELISA microplate reader. Negative control (NC) and positive control (PC) were designed to identify the effect of ETE in 3T3-L1 preadipocytes cells. The addition of insulin was considered as positive control which helps to enhance glucose uptake to the cells.

To measure the accumulation of triglycerides, adipocyte differentiation was induced at the end of the treatment period, which is a common measurement of PPAR $\gamma$ agonist activity. The differentiated adipocytes cells were fixed with formaldehyde and washed with distilled water. Oil-Red-O solution $(0.5 \%$ in isopropanol) was used to stain the cells and incubated for $1 \mathrm{~h}$. After washing, the fat droplets in 3T3-L1 adipocytes were monitored under microscope. The amount of triglyceride was determined by isopropanol dissolution and quantified by spectrophotometric analysis at $490 \mathrm{~nm}$.

The adipogenic markers expression such as PPAR $\gamma, \mathrm{C} / \mathrm{EBP} \alpha, \mathrm{GLUT} 4$, and IRS1 was determined by western blotting.

\section{Statistical analysis}

All data were presented as the means \pm standard deviation (SD). SPSS was used for the statistical data analysis. Between groups comparison were made by ANOVA analysis. It was followed by Duncan's Multiple Range Test (DMRT) where $P$-values less than 0.05 were considered significantly different.

\section{RESULTS AND DISCUSSIONS In vitro anti-inflammatory activity}

Inflammation is an early response to tissue injury and foreign pathogens, and then the normal tissue structure and function are recovered. A normal inflammatory response regulates expression of pro-inflammatory and anti-inflammatory proteins. During these inflammation responses, macrophages are essential cells that bridged innate and adaptive immunity (Park et al., 2016). Based on these observations, it has been hypothesized that inhibiting high-output NO, IL-6 and TNF $\alpha$ production in macrophages, by blocking iNOS and COX2 expressions or their activities, can 
serve as the basis for the potential development of anti-inflammatory drugs. Furthermore, nuclear factor- $x \mathrm{~B}$ (NF-kB)-dependent gene expression plays an important role in inflammatory responses and increases the expression of genes encoding cytokines and receptors involved in pro-inflammatory enzyme pathways such as iNOS and COX2. Recently, many studies have demonstrated the role of phytochemicals in anti-inflammatory activity is through downregulation of the NF-kB pathway (Kundu and Surh, 2005).

The toxic concentration of ETE in LPSstimulated RAW 264.7 cells was assessed via CCK-8 assay. Significant $(P<0.05)$ differences were observed in viability of macrophages RAW 264.7 cells treated with different concentration up to $400 \mu \mathrm{g} / \mathrm{ml}$ ETE compared with the control (Figure 1A). As the concentration of ETE increased up to $200 \mu \mathrm{g} / \mathrm{mL}$, the cell viability increased to greater than that of the control, and then started to decline.
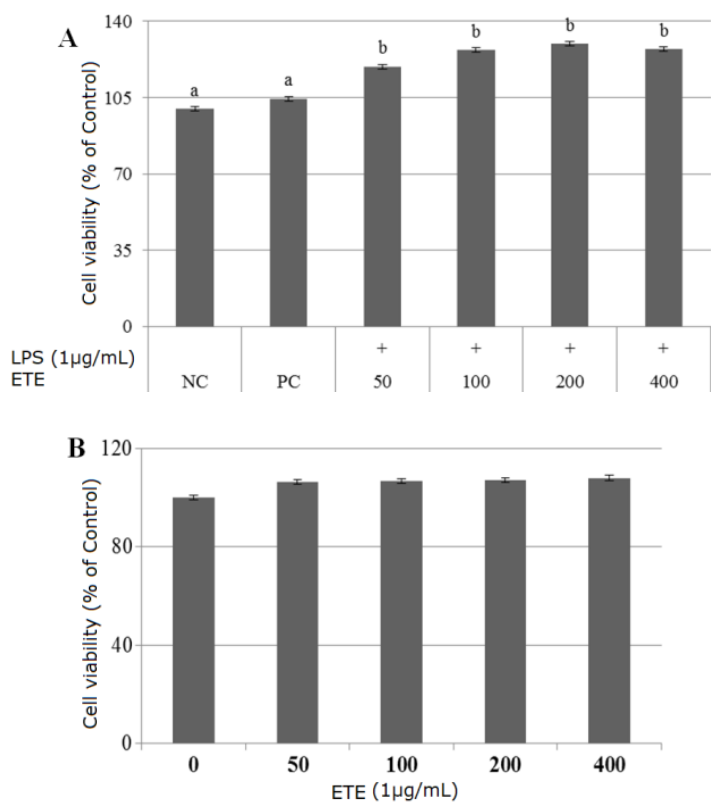

Figure 1. Effects of Euphorbia tithymaloides ethanol extract on the proliferation of RAW 246.7 machrophages stimulated with LPS (A) and 3T3-L1 preadipocytes (B) for 24h. The data presented as the means $\pm S D(n=6)$. Means with different superscript letters are significantly different $(P<0.05)$.
The nitrite detection method used in this study was a spectrophotometric assay based on the Griess reagent. In Figure 2A, the incubation of LPS-stimulated RAW 264.7 cells with ETE for $24 \mathrm{~h}$ resulted in significant NO production $(14.4 \mu \mathrm{M} / \mathrm{L})$. However, increases in the concentration of ETE up to $400 \mu \mathrm{g} / \mathrm{mL}$ significantly decreased NO production in RAW 264.7 macrophages (from $14.4 \mu \mathrm{M} / \mathrm{L}$ to $8.9 \mu \mathrm{M} / \mathrm{L}$ ). In addition, ETE inhibited expression of iNOS in a dose dependent manner (Figure 2B).
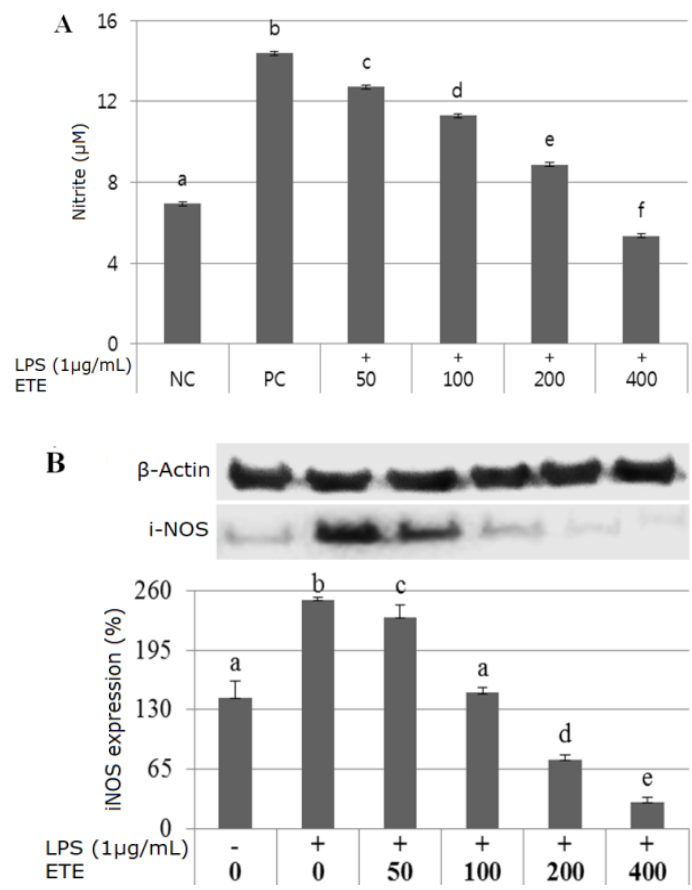

Figure 2. Effects of Euphorbia tithymaloides ethanol extract on $\mathrm{NO}$ production (A) and iNOS expression (B) in RAW 264.7 machrophages. The data are presented as the means \pm SD $(n=5)$. Means with different superscript letters are significantly different $(P<0.05)$.

ETE significantly inhibited NF-kB activation (Figure 3). The genes and protein expression of inflammatory cytokines decreased as the concentration of ETE was increased to $400 \mu \mathrm{g} / \mathrm{mL}$. As calculated from the images (Figure 3), ETE significantly inhibited LPS-stimulated NF-kB activation by $98 \% \quad(P<0.05)$ in dose-dependent manner. 
ETE also decreased the expression of $\mathrm{TNF} \alpha$, IL-6, and COX2, which leads to the amplification of inflammation. These results indicated that ETE applied an anti-inflammatory activity in LPS-stimulated RAW 264.7 macrophages by blocking $\mathrm{NF}-\mathrm{kB}$ activation.
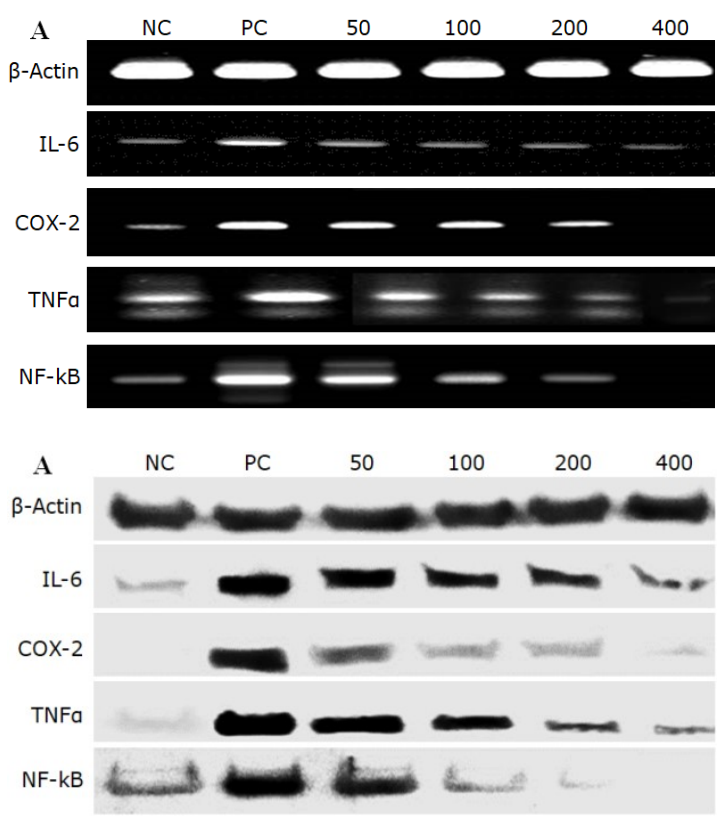

Figure 3. Effects of Euphorbia tithymaloides ethanol extract on genes (A) and protein (B) expression of pro-inflammatory cytokines in RAW 264.7 macrophages

The result of this study revealed the significant inhibitory activity of ETE in RAW 264.7 cells stimulated with LPS at doses up to $400 \mu \mathrm{g} / \mathrm{mL}$, which occurred through blockade of the NF-kB signaling pathways. NF- $\mathrm{kB}$ is one of the major expressions in the immune system and, regulates many pro-inflammatory cytokines expression that define responses to pathogen. The NF-kB transcription factor was activated by lipopolysaccharide in macrophages (Hayden and Ghosh, 2008). The activation of NF-kB leads to the induction of many proinflammatory cytokines expression (Baeuerle, 1991). After the cells are activated, NF-kB separates from inhibitory protein $(\mathrm{IkB} \alpha)$ which releases the p50/p65 heterodimer. Thereafter, it translocates owing to the nuclear localization signal and thereby induces the expression of pro-inflammatory genes and proteins. TNF $\alpha$ and interleukin function synergistically to induce the expression of several major pro-inflammatory mediators including prostaglandins, leukotrienes, and NO.

$\mathrm{NO}$ was involved in the regulation of diverse physiological and pathophysiological mechanisms in immunological systems. It acts as first line of defense against infection in the immune system. However, in inflammatory disorders, NO also acts as cytotoxic agent in some pathological activity because of its free oxygen radical (Alderton et al., 2001; Bogdan, 2001; Dawn and Bolli, 2002). LPS, which is isolated from bacteria, stimulates the macrophages production of $\mathrm{NO}$ by iNOS. COX-2 is related with NO production and its overproduction may cause inflammation and carcinogenesis (Park et al., 2004). In this study, NO production and COX-2 expression decreased by ETE in dose-dependent manner.

\section{In vitro anti-diabetic activity}

Diabetes is associated with abnormal metabolism of glucose which caused by various factors. One of the requirements of ideal antidiabetic agents is enhanced glucose uptake in most insulin target tissue (Navarro and Mora, 2006). Type II diabetes, formerly known as non-insulin dependent DM, is the most common form of DM characterized by hyperglycemia, insulin resistance, and relative insulin deficiency. This leads to a decrease in glucose transport into the liver, muscle cells, and fat cells. In skeletal muscle, insulin resistance can result from high levels of circulating fatty acid that disrupt insulin signaling pathways (Saraswathy et al., 2017). Insulin signaling, after binding to its specific receptor in adipocytes, regulates the storage of free fatty acids in the form of triglycerides; however, massive adipocytes produce a number of adipocytokines that consequently modulate insulin signaling with excess free fatty acids (Hassan etal., 2007). This present study discovered that ETE increased lipid accumulation, and significantly increased glucose uptake and GLUT4 expression in 3T3-L1 adipocytes.

As shown in figure $1 \mathrm{~B}$, ETE was not cytotoxic to cells below $400 \mu \mathrm{g} / \mathrm{ml}$. The cells were expressed as a percentage of cell viability compared with the untreated groups, which were considered to be $100 \%$ viable. No significant change in 3T3-L1 preadipocytes cell 
proliferation was observed even when the concentration of ETE was increased to $400 \mu \mathrm{g} / \mathrm{mL}(P>0.05)$. Therefore, these concentrations of ETE were selected for further experiments. ETE was found to significantly $(P<0.05)$ enhance adipogenesis in a dosedependent manner in 3T3-L1 preadipocytes (Figure 4A). The lipid accumulation by ETE in fully differentiated 3T3-L1 cells significantly increased as the concentration was increased to $400 \mu \mathrm{g} / \mathrm{mL}$ (Figure 4B).
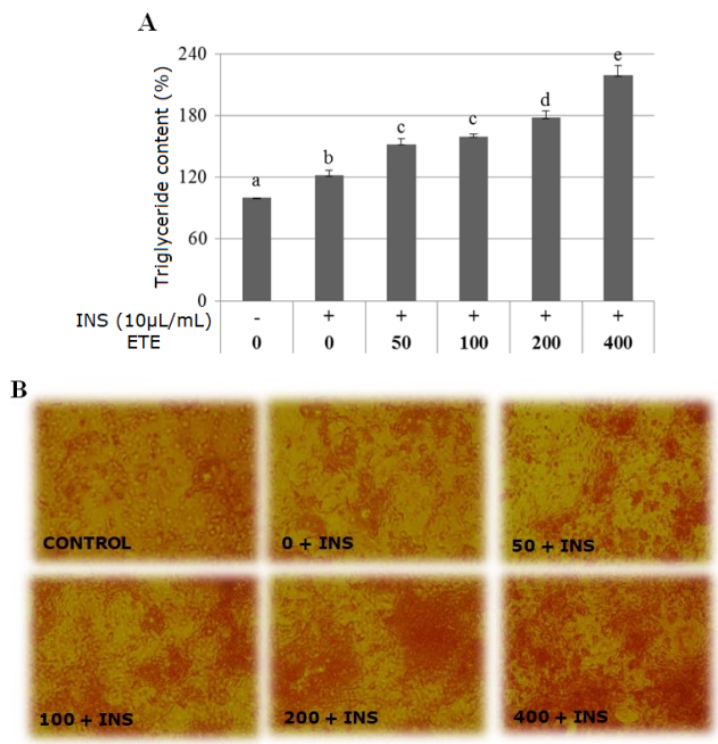

Figure 4. Effects of Euphorbia tithymaloides ethanol extract on triglyceride content (A) and adipogenesis (B) in fully differenteated 3T3-L1 preadipocytes. The data are presented as the means \pm SD $(n=6)$. Means with different superscript letters are significantly different $(P<0.05)$.

2-NBDG assay was used to examine the effects of ETE on glucose uptake. The results indicated that ETE significantly increased glucose uptake in a dose-dependent manner $(P<0.05)$. As shown in figure $5 \mathrm{~A}, 400 \mu \mathrm{g} / \mathrm{mL}$ ETE caused a two fold increase in glucose uptake in insulin-induced 3T3-L1 cells. Similarly, GLUT4 protein expression was also increased along with increasing the concentration of ETE (Figure 5B). In contrast, $1 \mu \mathrm{g} / \mathrm{mL}$ insulin increased GLUT4 expression of positive control and $400 \mu \mathrm{g} / \mathrm{mL}$ ETE by 8 and 13 - fold, respectively.

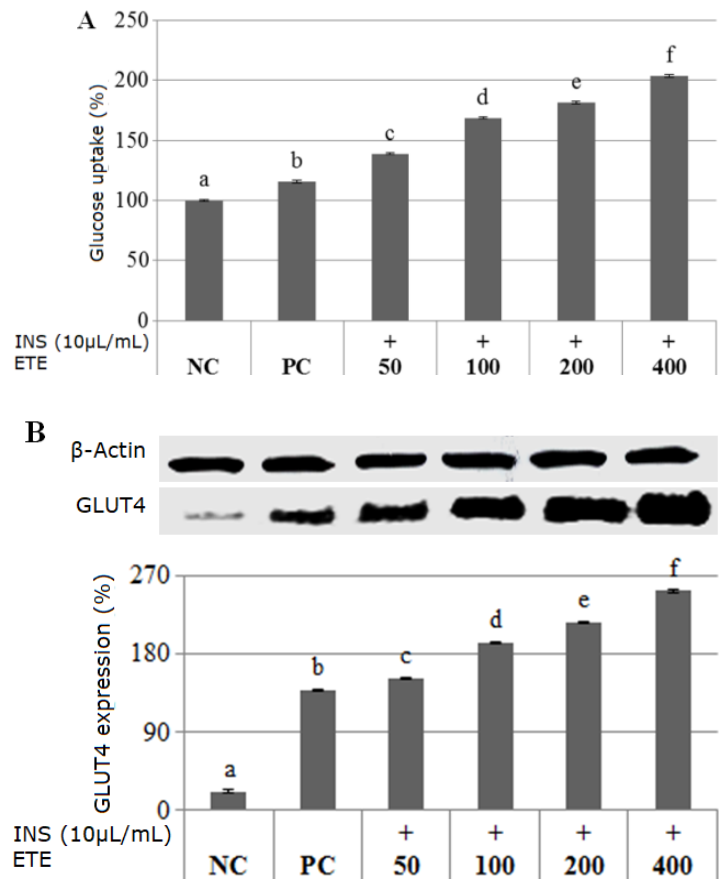

Figure 5. Effects of Euphorbia tithymaloides ethanol extract treatment for $24 \mathrm{~h}$ on glucose uptake (A) and GLUT4 expression (B) in fully differentiated 3T3-L1 preadipocytes. The data are presented as the means $\pm \mathrm{SD}(\mathrm{n}=5)$. Means with different superscript letters are significantly different $(\mathrm{P}<0.05)$

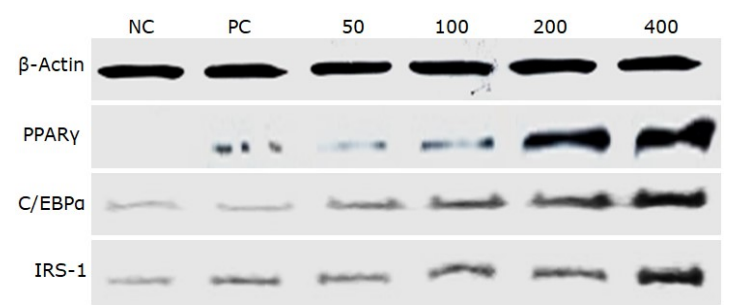

Figure 6. Effects of Euphorbia tithymaloides ethanol extract on protein expression of adipogenic markers in differentiated 3T3-L1 cells.

The expression of adipogenic markers, such as PPAR $\gamma, \mathrm{C} / \mathrm{EBP} \alpha$, and IRS-1 also significantly increased as the concentration of ETE increased (Figure 6). The upregulation of those expressions is very important in adipogenesis. Similarly, ETE also played an important role in the enhancement of insulin sensitivity, as shown by the observed increase in IRS-1 protein expression. These results 
suggested that the excellent anti-diabetic action of ETE occurred through the activation of insulin signaling pathways by insulin-sensitizing PPAR $\gamma$ agonists.

Adipogenesis is the process by which the undifferentiated precursor cells differentiate into fat cells. This is supported by the increase in the adipocyte genes expression such as $\operatorname{PPAR} \gamma$ and $\mathrm{C} / \mathrm{EBP} \alpha$. The activation of PPAR $\gamma$ is a key process in adipocyte differentiation. PPAR $\gamma$ regulates the genes expression related with insulin signaling pathways, as well as glucose and lipid metabolism in mature adipocyte (Bouaboula et al., 2005). In the present study, ETE activated PPAR $\gamma$, which induced the differentiation of 3T3-L1 preadipocyte. The results showed that ETE enhances adipogenesis in the presence of insulin in a dose-dependent manner; therefore, it can be considered to have insulin-like activity. Our results suggest that ETE may have the ability to increase insulin sensitivity through the activation of PPAR $\gamma$. Insulin stimulation in adipocytes leads to the translocation of GLUT4 to the cell surface by binding to insulin receptor proteins within the cell. Our results admitted the insulin-like and insulin sensitive's properties of ETE in experiments through the stimulation of 2-NBDG uptake into adipocytes.

The present study provided evidence that ETE enhances insulin sensitivity, as shown by the increased expression of IRS-1 proteins. Furthermore, it also significantly induced GLUT4 expression, which serves as an important role in insulin mediated glucose transport. In summary, E. tithymaloides inhibited NF-kB signaling pathways by blocking NF-kB activation. Furthermore, it also enhanced insulin sensitivity, which leads to enhanced uptake of glucose into adipocyte cells. These findings suggested that ETE is herbal component with potential use in the development of new immunomodulatory and anti-diabetic agents for treating inflammation and diabetes mellitus, respectively.

\section{CONCLUSIONS}

In our study, ETE administration increased NO production, inhibited the NF-kB pathway, and suppressed other pro-inflammatory cytokines expression in LPS- stimulated RAW 246.7 cells in a dosedependent manner. Furthermore, it also enhanced adipogenesis, stimulated 2-NBDG uptake, and increased insulin sensitivity through PPAR $\gamma$ upregulation. ETE demonstrated a clear potential to act as an immunomodulatory and anti-diabetic herbal medicine for treating inflammation and type II diabetes. However, further in vivo studies are necessary to verify the effectiveness of ETE in the treatment of these conditions. Furthermore, the identification of the active compounds in ETE is required to elucidate the mechanisms of action.

\section{ACKNOWLEDGEMENT}

The author's contributions are as follows: all authors collaborated in the design of the experiment, Seong Gu Hwang supervised for the whole duration of study; Joseph dela Cruz and Najuma Joshi are responsible for the writing and editing of the manuscript; Theresia Galuh Wandita conducted the experiment and also assisted in writing the manuscript. The authors declare no conflicts of interest to this work.

\section{REFERENCES}

Adzu B., Zakariya ST., Auta IK., and Katsayal UA. 2008; Assessing the potency of Pedilanthus tithymaloides latex against Plasmodium berghei berghei infected mice. Int. J. Biol Chem Sci. 2(2), 216-219.

Alderton WK., Cooper CE., and Knowles R. G. 2001; Nitric oxide synthases: structure, function and inhibition. Biochem J. 357(3), 593-615.

Baeuerle PA. 1991; The inducible transcription activator NF- $x \mathrm{~B}$ : regulation by distinct protein subunits. Biochim. Biophys. Acta (BBA)-Reviews on Cancer .1072(1), 63-80.

Bogdan C. 2001; Nitric oxide and the immune response. Nature Immunol. 2(10), 907-916.

Bouaboula M., Hilairet S., Marchand J., Fajas, L., Le Fur G., and Casellas P. 2005; Anandamide induced PPAR $\gamma$ transcriptional activation and 3T3-L1 preadipocyte differentiation. Eur. J. Pharmacol. 517(3), 174-181.

Castaldo S., and Capasso F. 2002; Propolis, an old remedy used in modern medicine. Fitoterapi.a 73, S1-S6. 
Choi SS., Cha, BY., Lee YS., Yonezawa, T., Teruya T., Nagai K., and Woo JT. 2009; Magnolol enhances adipocyte differentiation and glucose uptake in 3T3-L1 cells. Life Sci. 84(25), 908-914.

Dawn B., and Bolli R. 2002; Role of nitric oxide in myocardial preconditioning. Ann. N. Y. Acad. Sci. 962(1), 18-41.

Ghosh C., Hong B., Batabyal S., Jeon TI., Yang SH., and Hwang G. 2014; Antiinflammatory activity of the ethanol extract of Dictamnus dasycarpus leaf in lipopolysaccharide-activated

macrophages. BMC Complement Altern Med. 14(1), 330.

Hassan M., El Yazidi C., Landrier JF., Lairon D., Margotat A., and Amiot MJ. 2007; Phloretin enhances adipocyte differentiation and adiponectin expression in 3T3-L1 cells. Biochem. Biophys. Res. Commun. 361(1), 208-213.

Heinrich M., Rimpler H., and Barrera NA. 1992; Indigenous phytotherapy of gastrointestinal disorders in a lowland Mixe community (Oaxaca, Mexico): Ethnopharmacologic evaluation. J. Ethnopharmacol. 36(1), 63-80.

Jain SK., and Srivastava S. 2005. Traditional uses of some Indian plants among islanders of the Indian Ocean;

Joseph B., and Priya M. 2011; Review on nutritional, medicinal and pharmacological properties of guava (Psidium guajava Linn.). Int. J. Pharma Bio Sci. 2(1), 53-69.

Kundu JK., and Surh YJ. 2005; Breaking the relay in deregulated cellular signal transduction as a rationale for chemoprevention with antiinflammatory hytochemicals. Mutat. Res.. 591(1), 123-146.

Manaharan T., Ming CH., and Palanisamy UD. 2013; Syzygium aqueum leaf extract and its bioactive compounds enhances preadipocyte differentiation and 2-NBDG uptake in 3T3-L1 cells. Food Chem. 136(2), 354-363.

Navarro JF., and Mora C. 2006; Diabetes, inflammation, proinflammatory cytokines, and diabetic nephropathy. Sci. World J. 6, 908-917.
Njamen D., Talla E., Mbafor JT., Fomum, ZT., Kamanyi A., Mbanya JC., and Rí, JL. 2003; Anti-inflammatory activity of erycristagallin, a pterocarpene from Erythrina mildbraedii. Eur. J. Pharmacol. 468(1), 67-74.

Oliveira AMD., Conserva LM., de Souza Ferro, JN., Brito FDA., Lemos RPL., and Barreto E. 2012; Antinociceptive and anti-inflammatory effects of octacosanol from the leaves of Sabicea grisea var. grisea in mice. Int. J. Mol. Sci. 13(2), 15981611.

Park EJ., Min HY., Ahn YH., Bae, CM., Pyee JH., and Lee SK. 2004; Synthesis and inhibitory effects of pinosylvin derivatives on prostaglandin E 2 production in lipopolysaccharide-induced mouse macrophage cells. Bioorganic Med. Chem. Lett. 14(23), 5895-5898.

Rosen ED., Walkey CJ., Puigserver P., and Spiegelman BM. 2000; Transcriptional regulation of adipogenesis. Genes Dev. 14(11), 1293-1307.

Saraswathy M., Kalimuthu K., Chinnadurai V., and Juliet SY. 2017; In vitro Evaluation of Antidiabetic and Anti-Inflammatory Activity of Ethanolic and Methanolic Extracts of Ceropegia juncea. Br J Pharm Res., 15(2), 1-9.

Singh LW. 2011; Traditional medicinal plants of Manipur as anti-diabetics. J. Med. Plants Res. 5(5), 677-687.

Vergara EJS., Dela CJ., Kim CM., and Hwang, SG. 2016; Increased adipocyte differentiation may be mediated by extracellular calcium levels through effects on calreticulin and peroxisome proliferator activated receptor gamma expression in intramuscular stromal vascular cells isolated from Hanwoo beef cattle. Ital J. Anim. Sci. 15(2), 256263.

Winrow CJ., Kassam A., Miyata KS., Marcus SL., Hunter, J., Capone JP., and Rachubinski RA. 1996; Interplay of the Peroxisome Proliferator-activated Receptor and the Thyroid Hormone Receptor-signaling Pathways in 
Regulating Peroxisome Proliferatorresponsive Genes. Ann. N. Y. Acad. Sci. 804(1), 214-230.

World Health Organization. 2016. Prevalence data of diabetes in Philippines. Available from: URL: http://www.who.int/ diabetes/countryprofiles $/ \mathrm{phl}$ en.pdf?ua $=1$ 